\title{
Note: Ultrasonic liquid flow meter for small pipes
}

Yang Yu, and Guanghua Zong

Citation: Review of Scientific Instruments 83, 026107 (2012); doi: 10.1063/1.3687780

View online: http://dx.doi.org/10.1063/1.3687780

View Table of Contents: http://aip.scitation.org/toc/rsi/83/2

Published by the American Institute of Physics

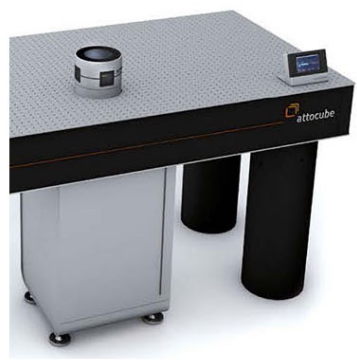

Obstruction free access

\section{attoDRY800}

attocube
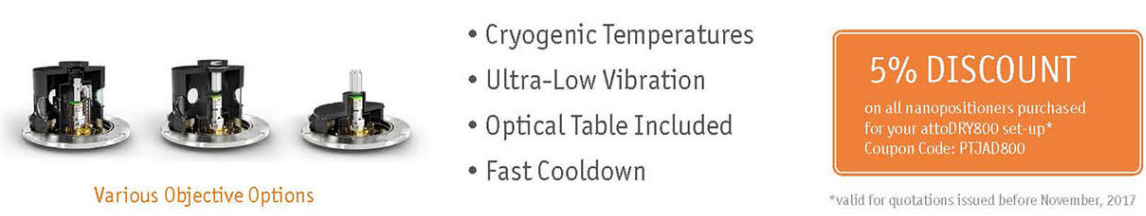

*valid for quotations issued before November, 2017 


\title{
Note: Ultrasonic liquid flow meter for small pipes
}

\author{
Yang Yu and Guanghua Zong \\ Robotics Institute, Beihang University, Beijing 100191, China
}

(Received 21 November 2011; accepted 2 February 2012; published online 21 February 2012)

\begin{abstract}
An ultrasonic flow meter for small pipes is presented. For metal pipe diameter smaller than $10 \mathrm{~mm}$, clamp-on ultrasonic contrapropagation flow meters may encounter difficulties if cross talk or the short acoustic path contributes to large uncertainty in transit time measurement. Axial inline flow meters can avoid these problems, but they may introduce other problems if the transducer port is not properly positioned. Three types of pipe connecting tees are compared using the computational fluid dynamics (CFD) method. CFD shows the $45^{\circ}$ tee has more uniform velocity distribution over the measuring section. A prototype flow meter using the $45^{\circ}$ tee was designed and tested. The zero flow experiment shows the flow meter has a maximum of $0.002 \mathrm{~m} / \mathrm{s}$ shift over $24 \mathrm{~h}$. The flow meter is calibrated by only 1 meter factor. After calibration, inaccuracy lower than $0.1 \%$ of reading was achieved in the laboratory, for a measuring range from 15 to $150 \mathrm{~g} / \mathrm{s}(0.29$ to $2.99 \mathrm{~m} / \mathrm{s}$; $R e=2688$ to 26876$)$. ( 2012 American Institute of Physics. [http://dx.doi.org/10.1063/1.3687780]
\end{abstract}

Commercial ultrasonic flow meters (UFM) are widely used in a lot of fields, such as water supply, petroleum, natural gas, etc. In these applications, clamp-on ultrasonic contrapropagation flow meters are widely used, where the pipes have a diameter of more than $100 \mathrm{~mm} .{ }^{1}$ However, in some circumstances, flow rate in small pipes needs to be measured, these pipes are usually smaller than $10 \mathrm{~mm}$. As a result, the acoustic path in these pipes is so short that brings more uncertainty to the transit time measurement.

Due to the problem encountered in clamp-on flow meter discussed above, a variety of axial offset flow meters have been proposed in the patent and literatures over the past 40 years. ${ }^{2,3}$ Most of these designs used $90^{\circ}$ tees to connect the measuring section and the inlet/outlet pipes; a few used $45^{\circ}$ tees in order to minimize the pressure drop. ${ }^{4}$

In our work, the influence of the connecting tees on the flow profile is investigated, so as to find an appropriate connecting tee for axial inline flow measurement, which would produce a relatively uniform velocity distribution over the measuring section. The flow profile simulated using the computational fluid dynamics (CFD) software (ANSYS/FLUENT 12.1) is shown in Fig. 1. Three types of connecting tees are compared, the first two are $90^{\circ}$ and $45^{\circ}$ tees, and third $0^{\circ}$ tee has an embedded transducer with two stands supporting the transducer. The black flakes on both sides out of the pipes represent the transducers. The entrance velocities are all set to $2 \mathrm{~m} / \mathrm{s}$, directions are from left to right. The stabilized velocities in the middle of the measuring section are $2.05 \mathrm{~m} / \mathrm{s}, 1.94 \mathrm{~m} / \mathrm{s}, 2.16 \mathrm{~m} / \mathrm{s}$, respectively, which indicates the $90^{\circ}$ and $45^{\circ}$ tees have less influence on the flow velocity. The black ellipses labeled 1-6 indicate the velocity transitional regions before the flow stabilizes; it shows the $90^{\circ}$ tee has a larger transitional region (1), which is not good for profile calibration. Most of the transitional regions in $45^{\circ}$ tee are in zero velocity, then there will be no time difference in these regions, so it has no influence on time measurement.

Based on the analysis above, $45^{\circ}$ tee is used in our axial inline flow meter design. The photograph of the proposed flow meter together with the signal processing electronics and transducer are shown in Fig. 2. The transducer is not wetted. It is coupled to a solid portion of the $45^{\circ}$ elbow, which forms part of the pressure boundary. All the pipes and connecting tees are made of titanium alloy, which makes the whole flow meter high strength and corrosion-proof, and weighs only $96 \mathrm{~g}$. The inside diameter of the metering pipe is $8 \mathrm{~mm}$, and the acoustic length is $200 \mathrm{~mm}$. The flow meter and electronics are quite small for system integration purpose. The ultrasound transducers are made of piezoelectric material with PEEK protective layer. The signal has a large leading edge on which to trigger, which helps improve the accuracy of time measurement. Three frequency transducers $(1 \mathrm{MHz}, 2 \mathrm{MHz}$, and $4 \mathrm{MHz}$ ) are designed for different application.

According to the principle of transit time method, when the fluid is flowing, the ultrasound transit time for downstream direction $t_{d}$ is less than upstream direction $t_{u}$, the difference between $t_{u}$ and $t_{d}$ is proportional to the velocity $v$, shown in Eq. (1)

$$
v=\frac{L}{2 \cdot t_{u} \cdot t_{d}} \cdot\left(t_{u}-t_{d}\right) .
$$

Here $L$ is the length of the acoustic path. The advantage of this method is that, it is not subject to temperature changes. As long as the transit time is measured, the fluid velocity can be calculated.

From the velocity along the acoustic path $v$, mass flow rate is calculated by

$$
Q=k \cdot \rho \cdot v \cdot \pi\left(\frac{d}{2}\right)^{2} .
$$

Here $\rho$ is the density of the fluid, $d$ is the inner diameter of the metering pipe. $k$ is the meter factor, it consists of several parts

$$
k=k_{v} \cdot k_{L} \cdot k_{t} \cdot k_{d} \cdot k_{T} .
$$

Those parameters $k_{v}, k_{L}, k_{t}, k_{d}, k_{T}$ are, respectively, the calibration factors for velocity profile, length of the acoustic 

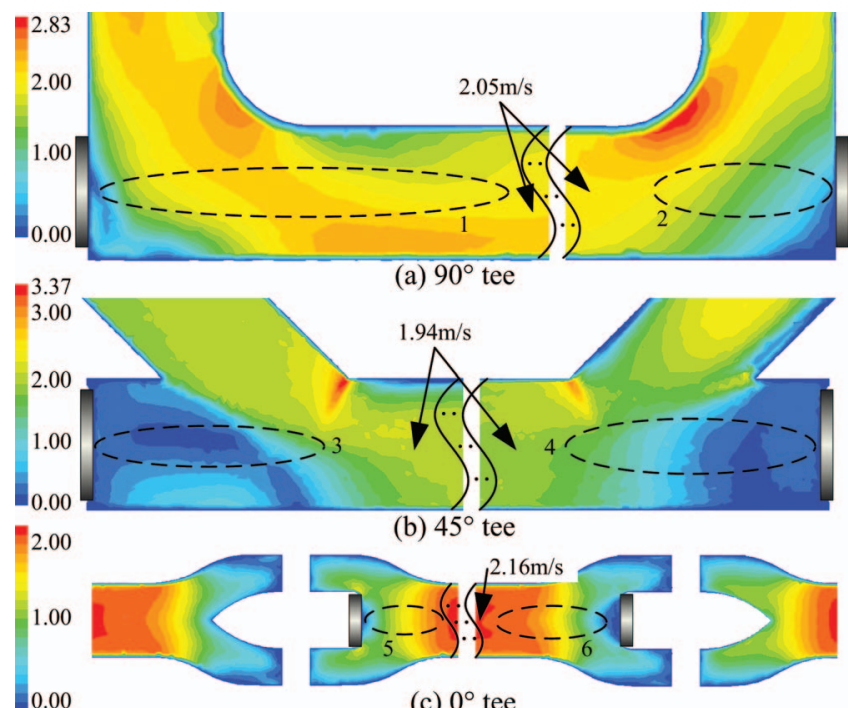

(b) $45^{\circ}$ tee



(c) $0^{\circ}$ tee

FIG. 1. (Color online) Flow profile simulation of three types of tees.

path, transit time, inner diameter of the metering pipe, and temperature. Those five parameters all influence the accuracy of the flow rate measurement, and it is hard and complicated to calibrate those parameters individually. So in the proposed flow meter, they are combined together as one parameter $k$. Due to the nonlinearity of parameters $k_{v}, k_{t}, k_{T}$, a look up table is built to calculate the meter factor $k$ under different measuring range and temperature.

Time-of-flight (TOF) is the only parameter that needs to be measured according to Eq. (1), so its accuracy is quite important. In our application, threshold comparison method ${ }^{5}$ is implemented. In the hardware, a time-to-digital converter (TDC-GP21, Acam, Germany) is served as the threshold comparator. In each measurement cycle, all the first three rising edges are trigged so that three TOF result will be obtained, which can be combined to improve the TOF measuring accuracy. The TOF result will be sent to microcontroller (ATmega 16A, Atmel, USA) for mass rate calculation and display.

The meter factor $k$ needs to be calibrated through experiment. The layout of the static weight based liquid flow calibration system is shown in Fig. 3. The uncertainty of the weighing platform is better than $0.05 \%$, provided by National

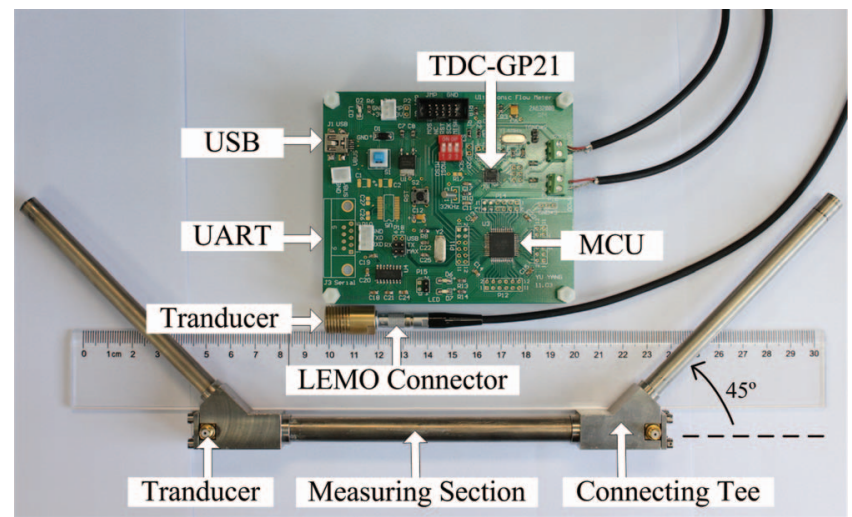

FIG. 2. (Color online) Photograph of the ultrasonic flow meter with the signal process electronics.

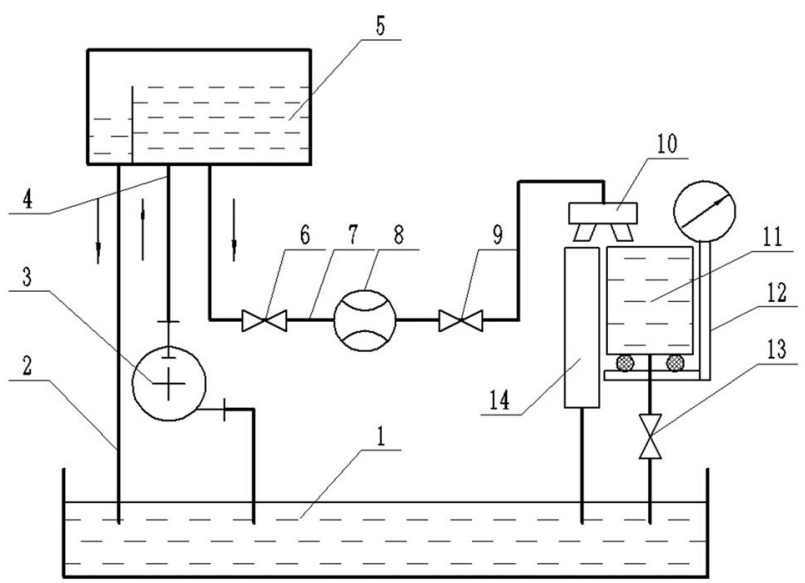

(1) Water tank, (2) drain, (3) pump, (4) inlet, (5) water tower, (6) stop valve, (7) test pipe, (8) Ultrasonic flow meter,

(9) regulator valve, (10) inverter, (11) weighing vessel,

(12) weighing platform, (13) drain, (14) by-pass valve

FIG. 3. Layout of static weight based liquid flow calibration system.

Institute of Metrology (Beijing, China). At first, the inverter (10) is switched to the by-pass valve (14), and an initial weight of the vessel (11) is recorded. Then the flow rate is regulated through the regulated valve (9); when the flow is stable, the inverter (10) is switched to the vessel (11), at the same time, the timer and the testing ultrasonic flow meter is switched on. When the preset volume of water is reached, the inverter (10) is switched to the by-pass valve (14) again, and final weight of the vessel is recorded. The standard flow rate can be calculated by dividing the weight change by the time lapse.

Calibration of the ultrasonic flow meter is conducted in the system described above. The environment temperature is $25^{\circ} \mathrm{C}$, humidity is $59 \% \mathrm{RH}$. The testing liquid is water of temperature $25.2{ }^{\circ} \mathrm{C}$. The measuring range of flow meter is set to $0-150 \mathrm{~g} / \mathrm{s}$ (equal to $0-2.99 \mathrm{~m} / \mathrm{s} ; \operatorname{Re}=0$ to 26876 ). Five points are chosen for calibration, they are $15 \mathrm{~g} / \mathrm{s}, 40 \mathrm{~g} / \mathrm{s}, 80 \mathrm{~g} / \mathrm{s}$, $120 \mathrm{~g} / \mathrm{s}, 150 \mathrm{~g} / \mathrm{s}$. All these points are in turbulent flow regimes, except $15 \mathrm{~g} / \mathrm{s}(\operatorname{Re}=2688)$ is in transitional

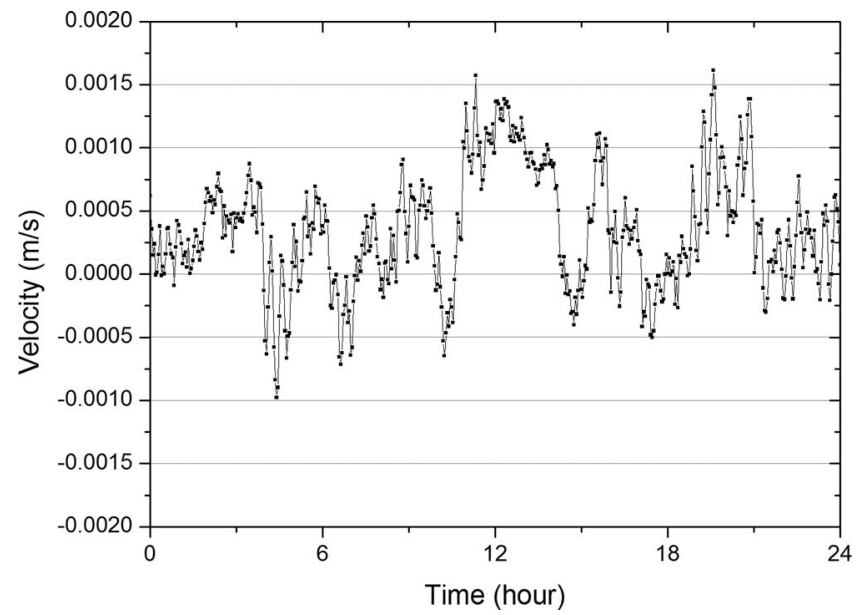

FIG. 4. Zero flow test result of the ultrasonic flow meter. 
TABLE I. Result of standard value and UFM readings.

\begin{tabular}{|c|c|c|c|c|c|}
\hline$i$ & $j$ & $\begin{array}{l}\text { Standard value } \\
\qquad\left(Q_{s}\right)_{i j}(\mathrm{~g} / \mathrm{s})\end{array}$ & $\begin{array}{c}\text { UFM reading } \\
Q_{i j}(\mathrm{~g} / \mathrm{s})\end{array}$ & $\begin{array}{c}\text { Factor } \\
K_{i j}=\left(Q_{s}\right)_{i j} / Q_{i j}\end{array}$ & $\begin{array}{c}\text { Error } \\
E_{i j}(\%)\end{array}$ \\
\hline \multirow[t]{3}{*}{1} & 1 & 15.189 & 14.056 & 1.0806 & -7.46 \\
\hline & 2 & 15.195 & 14.068 & 1.0801 & -7.42 \\
\hline & 3 & 15.192 & 14.081 & 1.0789 & -7.31 \\
\hline \multirow[t]{3}{*}{2} & 1 & 40.886 & 38.805 & 1.0536 & -5.09 \\
\hline & 2 & 40.887 & 38.821 & 1.0532 & -5.05 \\
\hline & 3 & 40.888 & 38.844 & 1.0526 & -5.00 \\
\hline \multirow[t]{3}{*}{3} & 1 & 78.625 & 75.623 & 1.0397 & -3.82 \\
\hline & 2 & 81.800 & 78.716 & 1.0392 & -3.77 \\
\hline & 3 & 78.677 & 75.680 & 1.0396 & -3.81 \\
\hline \multirow[t]{3}{*}{4} & 1 & 122.579 & 117.898 & 1.0397 & -3.82 \\
\hline & 2 & 122.583 & 117.842 & 1.0402 & -3.87 \\
\hline & 3 & 122.607 & 117.829 & 1.0406 & -3.90 \\
\hline \multirow[t]{2}{*}{5} & 1 & 152.561 & 146.859 & 1.0388 & -3.74 \\
\hline & 2 & 152.527 & 146.724 & 1.0396 & -3.80 \\
\hline
\end{tabular}

(laminar-turbulent) flow regime. An additional zero flow experiment is conducted to test the time drift of the ultrasonic flow meter, the inlet pipe is blocked to create a zero flow environment. Figure 4 shows the result, the average velocity of the $24 \mathrm{~h}$ result is $0.000035 \mathrm{~m} / \mathrm{s}$, and the maximum deviation is less than $\pm 0.002 \mathrm{~m} / \mathrm{s}$. It indicates the deviation mainly comes from the random noise, and the time shift is quite small.

The result of the five points calibration is shown in Table I. In each point, three measurements are taken. And based on these three measurements, calibration factor $K_{i j}$ is calculated by dividing the standard value $\left(Q_{s}\right)_{i j}$ with UFM's reading $Q_{i j}$. Error $E_{i j}$ is defined by

$$
E_{i j}=\frac{Q_{i j}-\left(Q_{s}\right)_{i j}}{\left(Q_{s}\right)_{i j}} \times 100 \% .
$$

The error shown in the table is relatively big, because the calibration factor is combination of five different parameters

TABLE II. Result of error and repeatability after water calibration.

\begin{tabular}{|c|c|c|c|c|c|}
\hline$i$ & $j$ & $\begin{array}{c}\text { Factor } \\
K_{i j}\end{array}$ & $\begin{array}{c}\text { Average factor } \\
K_{i}\end{array}$ & $\begin{array}{l}\text { Repetitiveness } \\
\qquad\left(E_{r}\right)_{i}(\%)\end{array}$ & $\begin{array}{l}\text { Calibrated error } \\
\qquad\left(E_{c}\right)_{i}(\%)\end{array}$ \\
\hline \multirow[t]{3}{*}{1} & 1 & 1.0806 & & & -0.065 \\
\hline & 2 & 1.0801 & 1.0799 & 0.081 & -0.020 \\
\hline & 3 & 1.0789 & & & 0.093 \\
\hline \multirow[t]{3}{*}{2} & 1 & 1.0536 & & & -0.050 \\
\hline & 2 & 1.0532 & 1.0531 & 0.048 & -0.011 \\
\hline & 3 & 1.0526 & & & 0.046 \\
\hline \multirow[t]{3}{*}{3} & 1 & 1.0397 & & & -0.019 \\
\hline & 2 & 1.0392 & 1.0395 & 0.026 & 0.031 \\
\hline & 3 & 1.0396 & & & -0.010 \\
\hline \multirow[t]{3}{*}{4} & 1 & 1.0397 & & & 0.048 \\
\hline & 2 & 1.0402 & 1.0402 & 0.043 & -0.003 \\
\hline & 3 & 1.0406 & & & -0.034 \\
\hline \multirow[t]{3}{*}{5} & 1 & 1.0388 & & & 0.036 \\
\hline & 2 & 1.0396 & 1.0392 & 0.039 & -0.034 \\
\hline & 3 & 1.0393 & & & -0.014 \\
\hline
\end{tabular}

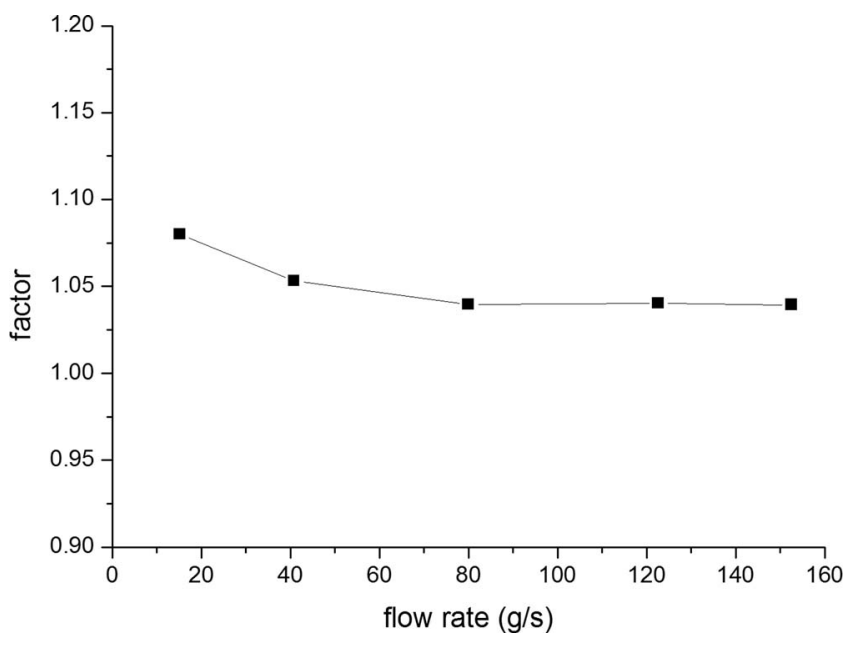

FIG. 5. Calibration factor curve.

as in Eq. (3). The length acoustic path is hard to measure accurately, and the fluid velocity profile factor varies with the flow rate.

Based on the factor calculated, the ultrasonic flow meter can be calibrated using the average factor $K_{i}$. The error and repetitiveness after calibration is shown in Table II. It shows the error is greatly decreased after calibration. The error is smaller than $0.1 \%$ in the full measuring range.

The meter factor $K_{i}$ is shown in Fig. 5. The curve shows the meter factor is more linear when the flow velocity gets bigger; this is because the flow is fully developed in high speed. In this calibration experiment, a demonstration of five flow points under $25^{\circ} \mathrm{C}$ is taken, so only 5 calibration factors is obtained. In order to build the look up table under all flow points and different temperature, more experiment is expected in future work.

In conclusion, an axial inline ultrasonic flow meter designed for small pipes is proposed. In order to investigate the influence of different connecting tees on the flow profile, CFD is used to simulate the flow condition near the inlet and outlet of the measuring section. The result shows, the $45^{\circ}$ tees have a relatively uniform velocity distribution. A prototype flow meter using $45^{\circ}$ tees is designed and tested. The zero flow experiment shows the proposed flow meter has a maximum of $0.002 \mathrm{~m} / \mathrm{s}$ shift over $24 \mathrm{~h}$. Instead of calibrating several parameters separately, those parameters are combined as 1 meter factor, which only need to be calibrated once. After calibration, inaccuracy lower than $0.1 \%$ of reading was achieved in the laboratory, for a measuring range from 15 to $150 \mathrm{~g} / \mathrm{s}$ ( 0.29 to $2.99 \mathrm{~m} / \mathrm{s} ; \mathrm{Re}=2688$ to 26876$)$.

${ }^{1}$ L. C. Lynnworth and Y. Liu, Ultrasonics 44, supplement, e1371 (2006).

${ }^{2}$ L. C. Lynnworth, Trans. Inst. Meas. Control (London) 3, 217 (1981).

${ }^{3}$ F. W. Noble, Rev. Sci. Instrum. 39, 1327 (1968).

${ }^{4}$ L. C. Lynnworth, Trans. Inst. Meas. Control (London) 4, 2 (1982).

${ }_{5}^{5}$ A. Carullo and M. Parvis, IEEE Sens. J. 1, 143 (2001). 